\title{
Belonging in the Online World: Older Adults' Use of Internet for Community
}

Belinda Grace Fuss

The University of Adelaide, Australia

Diana Dorstyn

The University of Adelaide, Australia

Lynn Ward

The University of Adelaide, Australia

\section{Abstract}

Objective: To explore older Australians' experiences of using computermediated communication (CMC) to engage with their social networks and communities.

Background: Use of CMC among older adults has been associated with favourable social outcomes. How older adults engage with others to foster these outcomes is less well known. Understanding this may be useful when developing programs to encourage older adults' use of CMC for social purposes.

Methods: In-depth semi-structured interviews with 12 adults (five women, seven men; aged 69 to 81) were conducted. Interview questions focused on individuals' use of CMC to engage with online communities. Data were transcribed and thematically analysed.

Results: Two overarching themes relating to a sense of Belonging and Support emerged. Belonging was most heavily emphasised, and included subthemes on how participants experienced their close social networks online, as well as their broader engagement with building interests and identity. Support arose to a lesser extent, and included subthemes relating to how CMC was used not only for the provision and receipt of such, but also to signal availability or need for support. Throughout, participants consistently weighed the benefits of CMC against the disadvantages.

Conclusion: The findings highlight the importance of social networks and online communities for older adults and, in particular, how CMC facilitates feelings of belongingness and provides opportunities for reciprocal instrumental, emotional, and informational support. Future research needs to consider the importance of having a sense of belonging when describing the social functioning of digitally literate older adults.

Key words: belonging, older adults, COVID-19, interest groups, computermediated communication

Corresponding author: Belinda Grace Fuss (belinda.fuss@adelaide.edu.au) 


\section{Introduction}

Older adults (aged 65 or older) are a growing population consisting of an estimated 700 million people globally $(9.1 \%$ of the global population, $12.5 \%$ of Oceania) (United Nations Department of Economic and Social Affairs, 2019). The Australian Government has highlighted loneliness and social isolation as particular concerns in this growing population, resulting in the Seniors Connected Program; a national initiative to promote local connections through telephone calling and increased supports for community groups (Australian Institute of Health \& Welfare, 2019; Australian Deparment of Social Services [DSS], 2021). Such initiatives are all the more relevant given the ongoing COVID-19 pandemic, which many predicted would exacerbate preexisting concerns around increasing levels of loneliness and social isolation (Goll et al., 2015; Rolandi et al., 2020).

Computer-mediated communication (CMC), defined as the human use of one or more electronic devices for communication, has been proposed as a way in which older adults can reduce loneliness and isolation, particularly for those with impaired mobility, or where key members of a social network are geographically dispersed (Nielsen, 2017; Woodward et al., 2013). CMC can take a number of forms, including but not limited to Web 1.0 (e.g. email, instant messenger) and Web 2.0 channels (e.g. social networking sites, online communities). The increased uptake of electronic communication amongst this age group makes CMC viable, with just over half of older Australians having accessed the internet in a given year (Australian Bureau of Statistics [ABS], 2017). Notably, programs designed to promote access to CMC (e.g. Be Connected; McCosker et al., 2020) have demonstrated benefits, including reductions in perceived loneliness as well as improved quality and/or quantity of social connections. The present study employs a qualitative methodology to investigate how older adults participate in computer-mediated social interaction to connect with others and whether CMC use can be used to reinforce and foster feelings of belonging and support.

\section{Background}

Research into the potential social benefits of CMC for older adults is mixed (Hage et al., 2016). Meta-analytic data suggest that older adults who use CMC are less likely to be lonely and depressed, although individual studies indicate that greater use of CMC may exacerbate psychological distress for those who were already lonely at baseline (Choi et al., 2012; Fang et al., 2019). More recent systematic reviews have indicated some benefit from CMC in terms of the social support and resilience that older adults experience (Fuss et al., 2019; Kamalpour et al., 2020). However, whilst feelings of belonging have been discussed as potentially mediating the relationship between CMC use and social outcomes, (Fuss et al., 2021; Fang et al., 2019; Yu et al., 2016), the potential link between belonging and the use of CMC has not been well studied in older adults.

The immediacy involved in CMC appears to allow for a greater sense of social connectedness, or a greater sense of being a part of the world, in addition to opportunities for affiliation and companionship - both considered central to the concept of social assurance (Lee-Won et al., 2015; Winter, 2011). Social affiliation and companionship are also theoretically crucial to the experience of belonging; the latter being a basic human need that causes stress when absent (Baumeister \& Leary, 1995; Lee \& Robbins, 1995). Importantly, feelings of belonging fostered through participation in community groups and social networks has been linked to reasons for living in older adults (Kissane \& McLaren, 2006). 
In this context, CMC allows older adults to communicate in a low-cost, easily accessible way (Doyle \& Goldingay, 2012; Harley et al., 2016). For example, video-conferencing (e.g., via Skype, Facetime) provides the opportunity for older adults to attend to significant moments in the lives of remote loved ones (Berg, 2017; Hill et al., 2015). Additionally, social exploration of interests and the shared acquisition of knowledge (e.g., through local interest groups) can help to promote one's identity and reinforce feelings of belonging. It may even be possible for online versions of these activities (e.g., games, dating, sharing information) to do likewise (Bruggencate et al., 2019; Clark, 2002; Harley et al., 2016; Hill et al., 2015; Nimrod, 2010). Indeed, early work indicates that participation in 'online communities', defined as communities where individuals come together based on a common interest rather than proximity or familiarity, allows older adults to have fun and access support from strangers (Pfeil et al., 2009; Wright, 2000; Xie, 2008). The extension of educational and social group activities into the digital realm - thereby constructing 'online' communities based around interests where members are known to each other - also has the potential to foster continued social interaction beyond that which may occur during formal meetings (Choi et al., 2012; Cohen-Mansfield \& Perach, 2015). Belonging to these local face-to-face groups is a form of social participation distinct to the interaction that older adults currently have with their close social networks (Goll et al., 2015). To date, extending participation from local groups to the online world has received limited attention within the CMC literature.

In saying this, it has also been argued that CMC may not be sufficient to support the relational intimacy necessary to foster feelings of belonging and emotional support, or the provision of intimate reassurance and care (Cohen \& McKay, 1984; Hage et al., 2016; Hagerty et al., 1993; Lee \& Robbins, 1995). There are a number of challenges associated with CMC compared to face-to-face or telephone communication - including fewer communication cues (e.g., tone of speech, facial expression, paralinguistic cues such as laughter etc.) and different social affordances (e.g., synchronicity, social presence, privacy, anonymity etc.) (Pfeil et al., 2009). Additionally, some older adults have expressed concerns surrounding security and exposure to inappropriate content (Erickson, 2011; Harley et al., 2016; Moult et al., 2018). There is also the possibility that interpersonal tensions may arise online. For example, when friends and family share misinformation-which might cause social strain and negatively impact on older adults' wellbeing (Chen \& Feeley, 2014). These challenges may explain why older adults report a preference for telephone calling rather than CMC, especially in times of distress (Harley et al., 2016; Lindley et al., 2009). In addition, theories of hyperpersonal communication suggest that attending to fewer cues places less pressure on the individual to maintain a particular image and allows for the formation of closer relationships through greater disclosure (Hill et al., 2015). As such, some older adults find seeking support online easier than face-toface interactions (Erickson, 2011). There is even evidence that older adults use CMC to engage in companionable activities, thereby reinforcing intimate confidant relationships with established social ties and helping individuals to explore their social world (Berg, 2017; Silva et al., 2018; Wright, 2000).

The available CMC research is, however, largely quantitative - relying on broad datasets and relatively narrow operationalisations of CMC use (e.g., use vs. non-use, frequency of use). Qualitative research can help us better understand the requirements needed for older adults to potentially benefit from CMC. Qualitative research allows researchers to investigate the lived experiences and perspectives that older adults have in relation to their own personal uses of CMC, including the potential benefits and limitations involved (Braun \& Clarke, 2013; Smith, 1996). Considering these perspectives may aid in the development of theory to resolve the seemingly paradoxical data that currently characterises this field.

In sum, although there may be difficulties in using CMC, digitally literate older adults do use this technology to keep in contact with, and access support from, close networks. This contact has the potential to foster feelings of belongingness, especially when individuals are able to 
access their interests online. The following study adds to this evidence base by investigating how older adults perceive their use of CMC and how use relates to their experiences of belonging and support.

\section{Research question}

This study was framed by the following, broad research question: "What are older Australian's experiences using CMC to engage with the social networks and communities to which they belong?" This question was considered by exploring experiences around: a) how older adults interact and engage with their social networks and communities online, b) perceived benefits and limitations in communicating with these online networks, and c) how this group exchange support with members of their social networks and communities via CMC.

\section{Method}

\section{Participant recruitment and eligibility}

Participants were originally recruited from a survey-based study conducted by the authors between November 2018 and April 2019 on older Australian users of CMC (Fuss et al., 2021). Recruitment was limited to older adults (aged $\geq 65$ ) living in Australia, and frequent (i.e., at least once a month) users of CMC - including video conferencing, instant messenger, social networking and email. Ten organisations catering to older adults (e.g., public libraries, Australian Seniors Computer Clubs Association, University of The Third Age etc.) agreed to assist with recruitment. Contact was made to these associations as they were deemed likely to include a number of older adults who actively use CMC. This strategy was necessary, given that users make up only half of the older adult population in Australia (ABS, 2017). Of 133 participants who completed the survey, 55 consented to a follow-up interview. Purposive sampling was then used to recruit a final sample of 12 participants based on the following criteria, obtained from this same survey: those who were older in age (i.e., 69+ years), and those who indicated high or low degrees of online social interaction (based on weekly face-toface interaction and use of CMC - daily vs. 1-2 days a week) and number of digital communication channels available (i.e. $\geq 3$ vs. 1) (see Table 1). The intention of these criteria was to capture a broad spread of participants in terms of how they interacted with others online and offline, and to what extent multiple modalities were used in so doing. Older age was targeted predominately because increased age predicts lower frequency of use amongst older adults (e.g., Silva et al., 2018). As such it was deemed important to understand the perspectives of those who have chosen to use CMC despite being less likely compared to the young-old.

The final sample comprised of seven males and five females aged between 69 and 81 years $(M=73.8, S D=5.2)$. Most were partnered, although three were single and living alone. All had been educated beyond high school, with five holding post-graduate qualifications. The majority were retired and income was wide-ranging (from AUD\$25,000 to >AUD\$200,000 per year, median $=$ AUD $\$ 50,000$ to $\$ 99,999)$. All self-reported very good or excellent physical health (see Table 1).

Table 1: Participant information

\begin{tabular}{|c|c|c|c|c|c|c|c|}
\hline ID & Pseudonym & Gender & Age & $\begin{array}{l}\text { Relationship } \\
\text { status }\end{array}$ & $\mathrm{CMC}^{*}$ & $\begin{array}{l}\text { Face- } \\
\text { to- } \\
\text { face }^{*}\end{array}$ & $\begin{array}{l}\text { Communication } \\
\text { channels }^{\dagger}\end{array}$ \\
\hline P01 & Gilbert & Male & 80 & Single & 7 & 7 & Email \\
\hline
\end{tabular}




\begin{tabular}{|c|c|c|c|c|c|c|c|}
\hline P02 & Cecil & Male & 80 & Married & 7 & 7 & $\begin{array}{l}\text { Email, } \quad \text { Facebook, } \\
\text { Linkedln }\end{array}$ \\
\hline P03 & Cathy & Female & 74 & Single & 7 & 7 & $\begin{array}{l}\text { Email, SMS, Facebook } \\
\text { Messenger }\end{array}$ \\
\hline P04 & Faith & Female & 76 & Married & 3 & 7 & $\begin{array}{l}\text { Email, SMS, } \\
\text { Facebook, WhatsApp, } \\
\text { Skype }\end{array}$ \\
\hline P05 & Jessie & Female & 80 & Married & 3 & 3 & Email, SMS \\
\hline P06 & George & Male & 70 & Married & 5 & 2 & $\begin{array}{l}\text { Email, SMS, } \\
\text { Facebook, WhatsApp, } \\
\text { Skype }\end{array}$ \\
\hline P07 & Lily & Female & 69 & Married & 7 & 7 & $\begin{array}{l}\text { Email, } \\
\text { WhatsApp, }\end{array}$ \\
\hline P08 & Nate & Male & 69 & Married & 7 & 7 & $\begin{array}{l}\text { Email, SMS, } \\
\text { WhatsApp, Facetime }\end{array}$ \\
\hline P09 & Rupert & Male & 81 & Married & 3 & 3 & Email, SMS, Facebook \\
\hline P10 & Peter & Male & 69 & Married & 4 & 3 & $\begin{array}{l}\text { Email, SMS, } \\
\text { WhatsApp, Skype }\end{array}$ \\
\hline P11 & Janet & Female & 70 & Single & 7 & 4 & Email, SMS \\
\hline P12 & Glen & Male & 80 & Married & 7 & 5 & Email, SMS \\
\hline
\end{tabular}

* Number of times per week.

${ }^{\dagger}$ From possible choice of channels used in the past month: Facebook, Facebook Messenger, Email, SMS, Whatsapp, Skype, Facetime, Linkedln, Twitter, Other (please specify). These channels were chosen as they were the nine most commonly used tools by Australian older adults at the time of survey development (Yellow, 2018).

\section{Procedure}

Participants were emailed the study information and a consent form, which they completed and returned. An email was subsequently sent to schedule a mutually convenient interview time. Interviews took place between the 7th of April and the 22nd of May 2020. Preliminary analysis was performed sequentially, with recruitment ceasing when no new information appeared in the interview data, indicating that saturation had been met (Braun \& Clarke, 2013). Interviews were conducted by the first author (BF). Ethics approval was obtained from the Human Research Ethics Subcommittee in the School of Psychology at the University of Adelaide (H-2019-93) prior to study commencement.

A qualitative methodology, involving semi-structured and in-depth telephone interviews, was employed. Questions examined the ways that this older adult group of CMC users engaged with their social networks and communities, including activities that are theorised to enhance belongingness, and questions about the potential for social support exchange, for example: "Can you tell me about a time when you've performed a companionable task while talking online?" (see Appendix A). Questions surrounding the benefits and limitations of communicating online and nuanced elements of social interaction (e.g., maintaining personal boundaries, managing others' expectations) were also included. Questions were used flexibly while remaining relevant to the research, thereby allowing participants to engage with their understanding of the question and to contribute what they wanted to the topics presented. For example, if a participant raised a topic that had not previously been considered or asked (e.g., 
several participants raised social support exchanges during COVID-19 very early in the interview), the interviewer responded to them rather than forcing a specific topic of discussion at the time. Two pilot interviews, both face-to-face and via telephone, were performed with individuals known to the first author, with feedback from these interviews then used to revise and finalise the interview schedule. This methodology was adopted with reference to suggestions by Braun and Clarke (2013), and is often used for qualitative research within the field of psychology (e.g., Young, Roberts \& Ward 2020).

Interviews were conducted during the initial stages of the COVID-19 pandemic in Australia. As face-to-face contact was limited at this time, interviews were conducted via telephone or VOIP (Voice Over Internet Protocol) audio-only calling. Video calling was considered, however as some participants were unable or unwilling to use this technology we selected a consistent form of interviewing across all participants. Audio was recorded using QuickTime (for Mac) screen recording. Interviews ranged from 30 to 90 minutes in duration (average $=66.4, \mathrm{SD}=$ 16.6) and were typically conducted in the one session, with a single participant requesting a break (this latter interview was performed over two days).

\section{Theoretical and analytical approach}

Inductive experiential realism was used to guide analysis, with CMC considered a practice that can be critically reviewed, but which can also be described in terms of experiences and how these translate meaningfully into participants' lives. Thematic analysis was applied to the interview data, as per the six stages outlined by Braun and Clarke (2013): familiarisation with data, coding, identifying, reviewing, and defining and naming themes. Transcription was carried out in NVivo software by the first author [BF], who became familiar with the data by listening to each recording at least twice. Complete coding was applied to the entire dataset by this same author [BF], compiled in NVivo (12.6.0), and assigned working definitions so that concepts could be refined and clarified as coding was performed. Codes (e.g., the code 'sharing' referred to 'social interaction for the purposes of engaging with/participating in an experience, spending time with others, and sharing knowledge/interests') and basic themes were grouped together based on theoretical and semantic interpretation, then structured under subthemes and overarching themes as they became apparent based on patterns within the data (see Appendix B). A total of 78 codes and basic themes were analysed within this process. Patterns were conceived to be ideas that appear both across the dataset and across participants (Braun \& Clarke, 2013). Those patterns that related directly to the research question were then designated as themes. Field notes were taken during the interviews and a journal maintained by the interviewer to consider how her personal experience and identity as a digital native might influence analysis. This journal included notes about how COVID-19 was affecting Australia in general so that historical context reflecting this period of great uncertainty and change could be applied to the findings at a later date if necessary. We believed this was especially important for the topic under investigation, as COVID-19 restrictions interrupted many forms of face-to-face communication for the broader population. The research team met on a fortnightly basis to discuss coding, data saturation, and emerging themes. Following the initial analysis of results all authors discussed the themes. The authors also discussed the analysis and the ways that themes were structured before findings were finalised.

\section{Results and Discussion}

Two overarching themes were identified in the data: Belonging and Support. Belonging was emphasised within the data as being of particular importance. Here 'belonging' referred both to participants' categorical membership within groups online (i.e., belonging to the University 
of the Third Age) and the experiences of belonging characterised by a connection to, and participation with, network members (i.e., feelings of belonging amongst family members). This theme comprised of subthemes related to participants experiencing close social networks through 'sharing news' and 'being in the moment', and their broader engagement associated with interests and identity through 'broadcasting information' and 'participating in interest groups' (see Supplementary file 1). The overarching theme Support arose to a lesser degree and included subthemes around the exchange of support with others, 'supporting others' and signalling availability or a need for support encapsulated through phrases like ' $R U$ Okay?'.

Participants additionally identified concerns with $\mathrm{CMC}$, describing this as a ddouble-edged sword' whereby the benefits experienced with CMC use were balanced against their concerns about privacy or instances of discomfort. This was not restricted to any one theme, but to experiences with CMC more broadly.

\section{Theme of Belonging}

This overarching theme related directly to how older adults used CMC to overcome barriers to their connection with, and participation within, their social world. For the majority, barriers focused on the separation caused by social and geographical distancing, and the need to plan around the busy lives of family and friends. Several participants cited additional barriers associated with telephone communication - including a general dislike of calling and difficulties associated with hearing impairment.

\section{Experiencing social networks}

This included the use of CMC to engage in rich, frequent and immediate communication with members of social networks - whether immediate family, chosen family, and/or close friends.

\section{Sharing news and catching up}

Participants exchanged news and updates, illustrated with photos, videos, and other media, with their social networks. Feedback was often instantaneous, however where time differences or other restrictions made immediate responses difficult, asynchronous communication was considered valuable as it allowed for both parties to take their time crafting a response to send at their leisure. CMC was described as especially important in enabling a sense of engagement, reinforcing strong links with families and friends. The importance of engagement is consistent with previous findings that a major motivation for the use of CMC among older adults is to maintain family connections (Harley et al., 2016). Specifically, participants enjoyed the way that minutia, not just major events, could be shared in this way. The ease of CMC meant that these low-effort exchanges could be frequent and incidental, which were beneficial in allowing participants to continue relationships spanning long periods of time, even decades, without physical interaction:

...somebody will put up a picture of um one of the grandkids doing something peca- interesting or cute or peculiar and everybody can pitch in and comment on it quickly so even though um you- y'know if you're relying on letters or the occasional phone call there wouldn't be that immediacy of contact and so on so it- it certainly helps for people whose families are dispersed to feel um, y'know, stronger links. [George, $M, 70$.

These exchanges were treasured when they were sent through dedicated communication 
channels and addressed to those who would be most interested in them. Irritation arose when these exchanges were seen as 'boring' or 'irrelevant' to the recipient or were sent through general channels without a dedicated target. Previous studies suggest that older adults can find the overly disclosive and 'sharing' culture of younger adults unappealing and somewhat concerning, with messages seen as attention-seeking, or inane, and disproportionately unimportant to the powerful medium they were shared through (Harley et al., 2018; Siibak \& Tamme, 2013):

...like: "I'm enjoying a coffee on the back terrace in the sunshine", well like big deal, do you need to send that message halfway around the world? [Rupert, $M$, 81.]

Sharing news often involved describing personal details, such as upcoming travel plans, along with private photos and family videos (e.g., those depicting children). Participants also expressed concerns about security, and understood the risk of their data being used in unanticipated and inappropriate ways. Many appeared to rely on an unwritten agreement of mutual social benefit with others, such that personal details would not be shared beyond their original purpose. This was demonstrated in one example where a participant described the choice of what details were disclosed based on which people were able to see the information, rather than the risk involved in using digital technology:

...it'd have to depend entirely on the who I was talking to ... um it's a different matter with- with our fam- direct family, the close family, there'sthere's no barrier to whatever we talk about [online] or um I- I guess in terms of WhatsApp you can select your groups ... very clearly. Facebook um I don't think that's possible. [Peter, M, 69.]

This concern was especially important for those who were at increased public visibility in their prior employment or roles, and amongst family members experiencing infighting - where information could be used for malicious attacks or as gossip fodder:

...l'm overly aware of the problems with ah with Facebook, um I was a teacher for um fifty-three years so and uh um I just ah w- was very aware of the negativity of uh some of the uh the comments- that l'd be a sitting duck actually. II wasn't but anyway. [Glen, M, 80.]

Additionally, there were concerns around scams (specifically people misrepresenting themselves) and data mining when sharing these details. All participants had some experience with - largely unsuccessful - attempts at these forms of privacy breaches in the past. While a certain amount of discomfort was expressed, many described themselves as highly competent and vigilant around cybersecurity. The suggestion is that older adults may be just as conscious of data security and privacy than their younger counterparts, if not more so (Kania-Lundholm \& Torres, 2015). As such, participants were acutely aware of what they discussed in public spaces online, and selected the tools they used to communicate based on how those tools approached security.

I stopped using Facebook because Facebook kept changing the parameters, so I would lock everything down so nothing was publishednobody could see anything etcetera etcetera and then l'd go in there a few 
weeks- months later, and find that all this stuff was open again. [Nate, $M$, 69.]

Despite this awareness, participants were not particularly concerned about their data being misused, with several noting that the information they shared online was typically not sensitive. Participants were therefore actively negotiating privacy and their expectations around breaches (Peine \& Neven, 2019).

\title{
Participating in the moment
}

Services such as video conferencing and instant messaging were typically used to contribute to activities performed by members of their social networks. As opposed to passive observation of these moments (e.g., through photos or video at a later date), this engagement demonstrates how older adults might participate in the complex interactions essential to maintaining a sense of belonging within their network (Hagerty et al., 1993). Example activities included babysitting grandchildren, working in the backyard, having barbeques, baking hotcross buns, going on nature hikes, evaluating real estate, welcoming a new pet, and sharing mealtimes. The use of CMC meant that these activities could be experienced without the filtering that commonly accompanies the relaying of news, thereby evoking feelings of closeness and togetherness with family and friends:

....y'know, warts and all. If the kids are having a meltdown you're you're there as as part of it all, so if they don't wanna eat their porridge or whatever ... you're very much a part of which is great. And that's, look, that's yanno doesn't make- doesn't make an artificially glossy idea of of uh what's going on in other people's lives and yanno we get over there as often as we can, but kids will be kids. [Peter, M, 69.]

This finding expands on previous research, whereby older adults use CMC to experience significant moments and milestones but also value engaging with every-day moments (Berg, 2017; Hill et al., 2015). Not all participants, however, were able to share occasions in this manner, describing difficulties around the availability and willingness of their friends particularly younger family members, who were often busy with child-rearing and work demands. For some this was a source of pain and dissatisfaction:

\begin{abstract}
I don't have um such light-hearted arrangements. I wish I- I could with my kids but they're not that kind of people, they're very driven, both of them ... [my daughter]'d be cooking, managing [her kids], and trying to talk to me and it- usual- and then the kids try to talk almost always compete to talk to me, compete with her and with each other and it ends up chaotic and I can see that my daughter is getting more and more tense and "this is not working, Mum", and you have to shut it down. [Faith, F, 77.]
\end{abstract}

Others found it difficult to multitask, or send media and provide a commentary on the activity, whilst some disliked the format of video-conferencing, suggesting it did not depict people in their best light and was somewhat intrusive. In both cases the benefits of sharing an interactive 'moment' over CMC did not appear to outweigh the difficulties, with participants indicating that they would prefer to engage in more direct exchanges of messages. 


\section{Building interests and identity}

This subtheme focused on the use of CMC to engage with personal interests and aspects of identity with those who are like-minded. CMC extended involvement beyond face-to-face meetings, allowing for more informal interaction and the development of deeper relationships. Although participants occasionally communicated about a particular topic with multiple people individually, most were also members of social clubs and associations. Engagement with formal and informal groups was described to a similar extent, with some accessing identities associated with being a member of a society, from their previous employment, and/or leadership roles that they had occupied within organisations.

\section{Broadcasting information}

Participants used services, such as social media, to broadcast information and share their opinion or expertise on topics relevant to their interests and identities. For some, online participation was integral to maintaining certain recreational and social interests, given that online platforms can provide older adults access to groups that are relevant to their identity, rather than only being age-based, in addition to providing opportunity for socialisation outside immediate networks (Harley et al., 2018). This involvement was seen as making a real contribution to society and provided a source of meaning, echoing previous findings that older adults can gain a sense of purpose and feelings of connectedness with the world when discussing topics of interests within online communities (Clark, 2002; Nimrod, 2010):

I'm very interested in the current affairs and uh particularly in the plight of refugees in Australia I mean I think this government's policy is disgusting so I mean I do I do tend to ah to send a few emails um sharing my opinion and um suggesting to a government what they can do to improve a situation ... so y'know and it's a- it's a way- it's- it's a way that the individual can have a voice ... I suppose l've got plenty of time to rattle as many cages as I can given the benefit of my opinion. [Lily, F, 69.]

Sharing allowed participants to use the skills and knowledge accrued over their lives despite being retired from the workplace. Such sharing brought saliency to identities developed over the course of careers, and a sense of ongoing contribution to their community:

Interviewer: so she would share that uh expertise that you have because you're a nurse

Janet: yep ... I try and relay factual stuff if it's based on experience and knowledge, you know. [Janet, F, 70]

Socialising also occurred within these groups, with discussion not necessarily limited to the specific interest or identity. Digital communication enabled the further development of online or offline friendships with acquaintances previously only linked by common interests and identities:

Like with the tennis- social tennis group there's about 15 people, well one of the ladies was up in uh Darwin, and um ... she was posting phophotographs and whatever else, and it was just an easy way for everybody 
to keep in touch. [Nate, M, 69.]

Many participants were involved in organisational roles for social interest groups and used $\mathrm{CMC}$ to keep track of details and make decisions regarding how the group was running. Email bulletins from such groups facilitated users' involvement and engagement in the group:

I'm the secretary of the of the uh Orange Masonic Lodge so then I'm using that all the time sending out meeting notices all the time. [Glen, M, 80.]

Discomfort and irritation arose where information shared in such groups was unsolicited or considered inappropriate. Although previous research has suggested this impacts on usage, it was not considered a sufficient reason to discontinue use, at least in the current sample (Erickson, 2011; Moult et al., 2018). A prevailing complaint was the frequency with which factually incorrect information or misinformation was shared, as in the case of friends and family sharing "fake news":

...some of the people who I listed as friends were using Facebook to promote the- some particular issue of their concern, either a religious proselytising or or promoting a particular political or environmental lobby group or something like that uh, and I just don't want to have that stuff coming on into my Facebook uh thing- I want to keep Facebook for, um basically for for personal matters ... as a result of which they got unfriended. [Rupert, $M, 81$.

The ways in which this discomfort was attended to depended on the person and the situation. Some maintained their boundaries by approaching the person sharing the information, and either correcting them or asking not to be involved in future sharing. Others actively adjusted the way they used certain platforms to limit exposure to similar messages in the future (e.g., curating their 'friends list' on Facebook, leaving a message group), whilst a few even opted to ignore the message. Similar strategies have been demonstrated by younger CMC users (Tandoc Jr et al., 2020). Many participants were therefore aware of the boundaries of others, careful to use appropriate forums for discussion, and responsive to the requests of others to not be involved in particular messages.

\section{Participating in interest group activities}

Engagement in online activities, such as dating, engaging in massive open courses (MOOCs) and playing games, was noted. These activities provided opportunities for stimulation and socialising with others, including meeting new people. Some specifically used this form of online engagement to cheer themselves up and to interact with others when they felt despondent:

I've made several friends which l've met in America when they've come here, um through p-playing um bridge online ... and that that's been a real um real asset in this COVID time 'cos it's a means of communication. You know, you're not only keeping this grey matter functioning, you're also interacting with others. And- and so it it it's a instead of drinking to- for entertainment, you're still communicating for entertainment ... "oh that was 
a good hand" or or "how you going today" or "oh gee you played that, whoops made a mistake". [Janet, F, 70.]

Participants actively employed strategies to determine whether or not they could trust the person they were talking with, and used the 'block' function within dating sites and games so that certain individuals could not contact them - or avoided particular online spaces if they did not feel safe:

I just say nicely yanno "I really don't think we have- that um we've got things uh in similar- similar things ... so maybe that we don't write" and then I block them. [Cathy, F, 74.]

Some interest groups that were previously run face-to-face continued to meet online during COVID-19, thereby allowing ongoing 'live' engagement in activities. Such an opportunity was seen as particularly beneficial during social distancing as it meant that participants didn't have to 'miss out' on their usual interactions with the club. Indeed, recent research suggests that older adults who were online during the pandemic felt more connected to others, than peers who were offline (Rolandi et al., 2020):

...just since this corona virus came in l've got Zoom because l'm doing a class through Zoom so l've only had one- one or two goes at that and l'm not that keen on it but but it's quite nice I I don't want to miss out on the class so I'm doing that. [Jessie, F, 80.]

However, such arrangements were also considered less than ideal compared to face-to-face meetings. Many noted that they would be returning to classes as soon as possible and believed that online meetings would not continue once social distancing restrictions were relaxed. Some were surprised by the number who were able to use technology, especially as certain forms (i.e., Zoom conferencing) were not commonplace prior to the pandemic. Others noted that they were not attending, or knew others who were missing out, because of difficulties with technology, or a general dislike of the format:

I'm a regular at two U3A classes but only one of them is Zooming, and I suspect it will stop as soon as we can do face-to-face again ... there are normally twenty-five people in it, and we're Zooming with ten to twelve, and I should think that the average age of the people is $80 \ldots$ only half are- are brave enough to try and get on. [Cecil, M, 80.]

\section{Theme of Support}

This overarching theme related to how participants used CMC to identify or express a need for support, and to engage in the processes of exchanging support. For some, the provision of support was feasible through online communication while face-to-face meetings were not possible and/or telephone calling was too expensive or not appropriate for the moment. For others, CMC provided a more comfortable environment for sharing than a face-to-face meeting or telephone call could offer. CMC was characterised by the ease with which participants could 'check in' and exchange support with others regardless of their location. 


\section{Supporting others}

The bulk of support occurred offline, with only a few participants engaging in emotional support exchanges via CMC. While CMC was often used to schedule meetings or phone calls, it wasn't seen as appropriate for the discussion of personal concerns. Rather, CMC was seen as less immediate, less intimate, less able to accurately convey tone, and more likely to cause undue confusion when compared with telephone calling and face-to-face meetings. If an issue was of particular urgency or sensitivity most participants noted that an in-person meeting or a telephone call would be their first preference:

I think a real time verbal conversation is a much more effective in conveying nuance and understanding than the Facebook post or anything. [George, M, 70.]

However, where the support was deemed instrumental or informative - such as internet banking to send money to a friend, job searching, sending something to make the other person smile, or providing a link to information about a specific problem - the ability to provide that support through a simple email or comment was appreciated, while still being understood as personal:

...although it was in a sense it was personal in another sense it wasn't personal because it was simply a a link to a website and I put that on Facebook um and that was very well received so that was easier much easier than creating an email or an SMS or having a pri- personal conversation. [Rupert, $M, 81$.

In discussing occasional instances of sharing support online, participants tended to describe situations where they provided support rather than when they were a recipient. There was a sense of purpose in being able to share their unique life experiences and wisdom with those in need of support. Research suggests that the provision of support allows older adults to feel needed and useful (Carstensen et al., 1999; Clark, 2002; Nimrod, 2010):

...she had all sorts of issues when she was overseas and she used to write to me quite frequently by email and I used to reply with what I thought ... and I tried to sort of give her the benefit of whatever wisdom I might have and so we kept in touch. [Jessie, F, 80.]

Conversely, those who had previously reported receiving low levels of support cited a desire to not burden others with what they saw as trivial concerns, especially where the other party was experiencing something that they perceived as troubling or distressing. This might be related to a more general desire to not be a burden and may even reflect the difficulties that some older adults have in asking for support (Cahill et al., 2009; Erickson, 2011):

I think it's more incumbent on me to uh, to use a stupid phrase to "soldier on" these days, it would be a bit self-indulgent to talk about ... talk specifically to somebody for um for support ... I think there aren't too many people in my world who want- want to hear them. [Faith, F, 76.] 
In observing others exchanging support online, the value of sharing and finding others to talk to was emphasised. Despite this, participants recognised that they would likely not put themselves in a situation where they would share their problems publicly online. An awareness of the differences in audience when discussing sensitive topics was identified. One-on-one communication, such as directed email, was preferred in comparison to the many-to-many communication via email or as a broadcasted conversation on Facebook:

I'd never been a part of or hadn't considered and I certainly didn't contribute to either so ... I thought in terms of what this fellow did in organising the original emails that was a really important lifeline to- to people out there to y'know open up a bit and uh get some support where they needed it. [Peter $M, 69]$

While somewhat inconsistent with precious findings that digital communication may make selfdisclosure online easier, this may also reflect participants' concerns around anonymity (e.g., where names are associated with accounts) (Hage \& Noseleit, 2015; Pfeil et al., 2009).

The biggest concern that arose in regard to support exchanges concerned communication preferences. For some, telephone communication was seen as ideal, whilst others preferred online communication. While many were willing to accommodate the communication preferences of their friends or family - for others, this was a point of irritation or discomfort. In some cases it was not possible to compromise due to functional barriers, such as hearing difficulties or distance, which made it difficult for supportive relationships to continue:

I've got friends who wanted to keep in touch with you but do it through email um not even SMS, and um they don't particularly want to talk on the phone um and so- and hold a conversation, and I find that very disconcerting. [Cathy, F, 74.]

\section{$R$ u okay?}

Participants found CMC beneficial for initiating support exchanges, particularly during the COVID-19 pandemic. These communications were often short texts or emails, including messages to let the person know they were thinking of them and offering support, reflecting the signalling of social presence; the awareness that others are available and involved in shared interaction (Walther, 1992). This support was described as reciprocal, as participants commented that friends also checked in on their wellbeing and offered opportunities to talk further:

[My friend] worries about me and wants to know whether l've eaten - the last email today was whether I had three meals today and she hopes that l've had plenty of good rest over the last two days. [Gilbert, $M, 80$.

Such messages were typically experienced as affectionate and appeared to open a dialogue around support without needing to ask for help explicitly. Recipients demonstrated their ability to identify and respond to the cues associated with social presence:

[She] SMS'd me and said "can we talk" ... so I rang her back and um and she just said "oh I just wanted to hear a human voice." [Faith, F, 76.] 
Although these exchanges were considered 'easy', their utility in reinforcing supportive relationships was appreciated. This was especially so when finding time for a sit-down talk was seen as difficult. In those cases, the ability to send short simple messages at any time was invaluable, as one older adult explained when describing her situation caring for a dying friend:

\begin{abstract}
...having email at night or a text that I could just touch base with those I cared about, because I was virtually offline to them, you know, I virtually didn't have the time, I was emotionally dealing with [the situation] ... but we got through it and um if I didn't have text and emails I- ... you know, I'm three months and l'd get- l'd send them a text "don't worry Nan," um "we know you're doing something good and we can wait." [Janet, F, 70.]
\end{abstract}

Alternatively, some became aware that a friend or family member was struggling when they posted about their problem on social media, and were able to respond by offering support. The ease with which this was possible was echoed by one participant who described the inverse - the pain involved in imbalanced support relationships:

I haven't made that point quite clear but that is a reflection of the- the normal speed and ease with which brief but significant communications can be made and are made all the time using y'know ... you just know that someone's out there they've they've got a connection with you but and itbecause it's so easy to do, when it doesn't happen it has more- more of an impact, I think. [Faith, F, 76.]

\title{
Conclusion
}

The current study explored the experiences of Australian older adults using CMC to engage with their communities. For this sample, a sense of belongingness within their social networks, which included family and friends, was emphasised as being an important benefit of being able to use CMC. Belonging was predominately facilitated through the ability to have dynamic exchanges of information and news, and through opportunities for participation in activities and occasions. Belonging within interest groups was reinforced in similar ways, with CMC supporting discussion about specific topics and participation in activities with like-minded others. This finding aligns with central tenets of belongingness theory, whereby social connectedness occurs through reinforced connections between individuals whilst social assurance is exhibited through shared participation in social activities (Baumeister \& Leary, 1995; Lee \& Robbins, 1995). Additionally, our findings expand upon research which is beginning to explore how older adults foster group belonging by establishing spaces for community online (Bruggencate et al., 2019; Harley et al., 2016). Intimate relationships developed and maintained within these groups could then be relied upon for support, as per theories on belonging and the social support processes (Carstensen et al., 1999; Hagerty et al., 1993; Lee \& Robbins, 1995; Nimrod, 2010; Pfeil et al., 2009). Notably, those involved in this study largely focused on how they used CMC to aid others rather than accessing support for themselves - perhaps reflecting the importance many older adults place on selfmanagement and independence (Kendig \& Browning, 2016). Studies have previously demonstrated the potential for CMC to enable older adults to access support that is emotional, instrumental, and informational (Kamalpour, Watson \& Buys, 2020). This study adds needed detail to the available research, particularly around the value of reciprocal support and a preference for offline support where topics are particularly sensitive. Participants constantly 
balanced the benefits of CMC use against the potential risks and negatives. This was particularly apparent when discussing the risks involved security and access to inappropriate content, consistent with previous studies (Erickson, 2011; Harley et al., 2016; Moult et al., 2018). Although these drawbacks caused discomfort, participants demonstrated aptitude in overcoming and navigating these difficulties - as per the findings from previous CMC studies with older adults (Kania-Lundholm \& Torres, 2015).

The current findings demonstrate that older adults are able to engage with multiple spheres of their social world using CMC, fostering feelings of belonging to important network groups while navigating the potential risks and downsides of using this technology. Our findings have several important practical implications. Firstly, facilitators of local community groups populated by older adults may wish to include a digital forum for participation, such as an online community or ongoing access to video-streamed meetings. This might offer those who are unable to physically access the local group at a particular time (e.g., during social distancing), the opportunity to still foster a sense of belonging and gain access to social support through inclusion. The security concerns and preferences listed by participants might also guide the parameters of such a group, for example a standalone website or forum with member-only access, as opposed to a publicly available Facebook group. Secondly, government initiatives such as the Seniors Connected Program and Be Connected might consider offering older adults practical support in finding online communities and interest groups that suit their interests and preferences. This support would not only help to promote the digital skills of older adults, through continual practice and the incentive of connection, but has the potential to reduce their experiences of social isolation and loneliness through inclusion, in line with the very aims of these initiatives (McCosker et al., 2020; DSS, 2021).

We recognise the strengths and limitations involved in this study. Our cross-sectional sample included both intense and casual CMC users defined in terms of the range and frequency with which online platforms were accessed. This facilitated a broad and nuanced understanding of how this group, as a whole, engage with online communities and social networks. However, the group we interviewed was quite homogenous in relation to their health status and education. As a result, this group may have faced fewer barriers to CMC involvement than might be seen in the broader, diverse older adult population (Hunsaker \& Hargittai, 2018). Additionally, adequate resources may underpin the way these participants focused on their ability to provide support to others and the opportunities they had for belonging. This may explain why this study differs from other research focused on how older adults use CMC to access support. We also recognise that not all older adults are involved in interest groups to the same degree as our sample, however we believe that individuals interviewed offered us key insights into how interest group involvement can be extended beyond face-to-face attendance.

Interviewing individuals as COVID-19 emerged in Australia produced a somewhat unique opportunity whereby we could investigate use of CMC in managing this social change, including the exchange of support and finding alternatives for social interaction. Although many close social networks and interest groups may continue to rely on online communication in the future, some may not - particularly as face-to-face activities resume. It may be worthwhile for these interest groups to promote opportunities for ongoing participation for those who would otherwise be unable to use digital means (e.g., University of the Third Age Online; Swindell et al., 2011). Future research may also wish to delve deeper into the importance that older adults place on CMC as a resource for belonging. Opportunities for social support have, to date, been the focus of much research around the social uses of CMC by older adults. This 
study indicates that opportunities for belonging may be equally important, if not more so.

This study describes, first and foremost, the importance of belonging as maintained and fostered in older adults through the use of CMC. Specifically, we detail how these individuals appreciated the ability to participate in activities and engage with their social networks and interest groups. This participation and engagement appeared to foster the feelings of social connectedness and assurance that are central tenets of belonginess theory. We also outlined the online support processes that are valued by this group - including a need for, or availability of, emotional, instrumental, and/or informational support which, combined with a sense of belonging, is perceived as valuable to the wellbeing of older adults. Online experiences were not without their difficulties, with discomfort and frustration experienced when socially engaging through CMC. Importantly, individuals were able to overcome this discomfort, or at least reduce the possibility of similar occurrences in the future. Practical implications and possibilities for future research raised by these findings are discussed.

\section{References}

Australian Bureau of Statistics (2017). Household Use of Information Technology, Australia, 2016-17. Retrieved 2/2/2019, from http://www.abs.gov.au/ausstats/abs@.nsf/mf/8146.0

Australian Institute of Health and Welfare (2019). Social Isolation and Loneliness. Retreived 7/6/2021, from https://www.aihw.gov.au/reports/australias-welfare/social-isolationand-loneliness

Australian Department of Social Services (Updated May, 2021). Seniors Connected Program. Retreived 7/6/2021, from https://www.dss.gov.au/communities-and-vulnerablepeople-programs-services/seniors-connected-program

Baumeister, R. F., \& Leary, M. R. (1995). The need to belong: desire for interpersonal attachments as a fundamental human motivation. Psychological Bulletin, 117(3), 497529. DOI: $10.4324 / 9781351153683-3$

Berg, T. (2017). 'Although we're isolated, we're not really isolated': The value of information and communication technology for older people in rural Australia. $J$ Med Internet Res. DOI: 10.2196/jmir.7209

Braun, V., \& Clarke, V. (2013). Successful qualitative research: A practical guide for beginners. Sage.

Bruggencate, T., Luijkx, T., Katrien, G., \& Sturm, J. (2019). When your world gets smaller: How older people try to meet their social needs, including the role of social technology. Ageing \& Society, 39(8), 1826-1852. DOI: 10.1017/S0144686X18000260

Cahill, E., Lewis, L. M., Barg, F. K., \& Bogner, H. R. (2009). "You Don't Want to Burden Them" Older Adults' Views on Family Involvement in Care. Journal of Family Nursing, 15(3), 295-317. DOI: 10.1177/1074840709337247

Carstensen, L. L., Isaacowitz, D. M., \& Charles, S. T. (1999). Taking time seriously: A theory 
of socioemotional selectivity. American psychologist, 54(3), 165. DOI: 10.1037//0003066X.54.3.165

Chen, Y., \& Feeley, T. H. (2014). Social support, social strain, loneliness, and well-being among older adults: An analysis of the Health and Retirement Study. Journal of Social and Personal Relationships, 31(2), 141-161. DOI: 10.1177/0265407513488728

Choi, M., Kong, S., \& Jung, D. (2012, Sep). Computer and internet interventions for loneliness and depression in older adults: a meta-analysis. Healthc Inform Res, 18(3), 191-198. DOI: 10.4258/hir.2012.18.3.191

Clark, D. J. (2002). Older adults living through and with their computers. Computers, informatics, nursing : CIN, 20(3), 117-124. DOI: 10.1097/00024665-20020500000012

Cohen-Mansfield, J., \& Perach, R. (2015). Interventions for alleviating loneliness among older persons: a critical review. American Journal of Health Promotion, 29(3), e109-e125. DOI: 10.4278/ajhp.130418-lit-182

Cohen, S., \& McKay, G. (1984). Social support, stress and the buffering hypothesis: A theoretical analysis. In A. Baum, S. E. Taylor, \& J. E. Singer (Eds.), Handbook of psychology and health (pp. 253-267). Lawrence Erlbaum. DOI: 10.4324/9781003044307-10

Doyle, C., \& Goldingay, S. J. (2012). The rise of the 'silver surfer': Online social networking and social inclusion for older adults. Journal of Social Inclusion, 3(2), 40-54. DOI: $10.36251 /$ josi.54

Erickson, L. B. (2011). Social media, social capital, and seniors: The impact of Facebook on bonding and bridging social capital of individuals over 65. AMICS 2011 Proceedings - All Submissions AMICS 2011. Retrieved 01/03/2019, from https://core.ac.uk/download/pdf/301352003.pdf

Fang, Y., Chau, A. K., Fung, H. H., \& Woo, J. (2019). Loneliness shapes the relationship between information and communications technology use and psychological adjustment among older adults. Gerontology, 65(2), 198-206. DOI: $\underline{10.1159 / 000495461}$

Fuss, B. G., Dorstyn, D., \& Ward, L. (2019). Computer-mediated communication and social support among community-dwelling older adults: A systematic review of crosssectional data. Australasian Journal on Ageing, 38(4), e103-e113. DOI: 10.1111/ajag. 12703

Fuss, B. G., Dorstyn, D., \& Ward, L. (2021). Social function and psychological wellbeing among older Australian users of computer-mediated communication: does social distancing impact use? Behavior \& Information Technology. DOI: 10.1080/0144929X.2021.1968952

Goll, J. C., Charlesworth, G., Scior, K., \& Stott, J. (2015). Barriers to social participation among lonely older adults: The influence of social fears and identity. PloS one, 10(2), e0116664. DOI: 10.1371/journal.pone.0116664

Hage, E., \& Noseleit, F. (2015). Changes and variations in online-and offline communication patterns: Including peer effects. DOI: 10.1108/ITP-09-2014-0216 
Hagerty, B. M., Lynch-Sauer, J., Patusky, K. L., \& Bouwsema, M. (1993). An emerging theory of human relatedness. Image: The Journal of Nursing Scholarship, 25(4), 291-296. DOI: $10.1111 /$ j.1547-5069.1993.tb00262.x

Harley, D., Morgan, J., \& Frith, H. (2018). Cyberpsychology as everyday digital experience across the lifespan. Springer. DOI: 10.1057/978-1-137-59200-2_9

Harley, D. A., Howland, K., \& Harris, E. C. (2016). Trajectories to community engagement: Understanding older people's experiences of engagement with online and local communities. The Journal of Community Informatics, 12(1). DOI: 10.15353/joci.v12i1.3213

Hill, R., Betts, L. R., \& Gardner, S. E. (2015). Older adults' experiences and perceptions of digital technology: (Dis)empowerment, wellbeing, and inclusion. Computers in Human Behavior, 48, 415-423. DOI: 10.1016/j.chb.2015.01.062

Hunsaker, A., \& Hargittai, E. (2018). A review of Internet use among older adults. New Media \& Society, 20(10), 3937-3954. DOI: 10.1177/1461444818787348

Kamalpour, M., Watson, J., \& Buys, L. (2020). How can online communities support resilience factors among older adults. International Journal of Human-Computer Interaction, 36(14), 1342-1353. DOI: 10.1080/10447318.2020.1749817

Kania-Lundholm, M., \& Torres, S. (2015). The divide within: Older active ICT users position themselves against different 'Others'. Journal of aging studies, 35, 26-36. DOI: 10.1016/j.jaging.2015.07.008

Kendig, H., \& Browning, C. (2016). Social research and actions on ageing well. In H. Kendig, P. McDonald, \& J. Piggott (Eds.), Population Ageing and Australia's Future (pp. 137163). ANU Press. DOI: 10.22459/paaf.11.2016.07

Knight, M. B., \& Pearson, J. M. (2005). The changing demographics: The diminishing role of age and gender in computer usage. Journal of Organizational and End User Computing, 17(4), 49-65. DOI: 10.4018/joeuc.2005100103

Kissane, M., \& McLaren, S. (2006). Sense of belonging as a predictor of reasons for living in older adults. Death studies, 30(3), 243-258. DOI: 10.1080/07481180500493401

Lee-Won, R. J., Herzog, L., \& Park, S. G. (2015). Hooked on Facebook: The role of social anxiety and need for social assurance in problematic use of Facebook. Cyberpsychology, Behavior, and Social Networking, 18(10), 567-574. DOI: 10.1089/cyber.2015.0002

Lee, R. M., \& Robbins, S. B. (1995). Measuring belongingness: The social connectedness and the social assurance scales. Journal of counseling psychology, 42(2), 232-241. DOI: 10.1037/0022-0167.42.2.232

Lindley, S. E., Harper, R., \& Sellen, A. (2009). Desiring to be in touch in a changing communications landscape: attitudes of older adults. Proceedings of the SIGCHI Conference on Human Factors in Computing Systems. DOI: $10.1145 / 1518701.1518962$

McCosker, A., Tucker, J., Critchley, C., Hiruy, K., Walshe, J., Suchowerska, R., \& Barraket, J. (2020). Improving the digital inclusion of older Australians: the social impact of Be 
Connected. Swinbourne University of Technology, Melbourne. DOI: 10.25916/5ed5b6e204a95

Moult, A., Burroughs, H., Kingstone, T., \& Chew-Graham, C. A. (2018). How older adults selfmanage distress-does the internet have a role? A qualitative study. BMC family practice, $\quad 19(1), \quad 1-8 . \quad$ DOI: $\quad 10.1186 / s 12875-018-0874-7$

Nielsen, M. I. S. (2017). Computer-mediated communication and self-awareness-A selective review. Computers in Human Behavior, 76, 554-560. DOI: 10.1016/j.chb.2017.08.015

Nimrod, G. (2010). Seniors' online communities: a quantitative content analysis. The Gerontologist, 50(3), 382-392. DOI: 10.1093/geront/gnp141

Peine, A., \& Neven, L. (2019). From intervention to co-constitution: new directions in theorizing about aging and technology. The Gerontologist, 59(1), 15-21. DOI: 10.1093/geront/gny050

Pfeil, U., Zaphiris, P., \& Wilson, S. (2009). Older adults' perceptions and experiences of online social support. Interacting with Computers, 21(3), 159-172. DOI: 10.1016/j.intcom.2008.12.001

Rolandi, E., Vaccaro, R., Abbondanza, S., Casanova, G., Pettinato, L., Colombo, M., \& Guaita, A. (2020). Loneliness and Social Engagement in Older Adults Based in Lombardy during the COVID-19 Lockdown: The Long-Term Effects of a Course on Social Networking Sites Use. International journal of environmental research and public health, 17(21), 7912. DOI: 10.3390/ijerph17217912

Siibak, A., \& Tamme, V. (2013). 'Who introduced granny to Facebook?': An exploration of everyday family interactions in web-based communication environments. Northern lights: Film \& media studies yearbook, 11(1), 71-89. DOI: 10.1386/nl.11.1.71_1

Silva, P., Delerue Matos, A., \& Martinez-Pecino, R. (2018). Confidant Network and Quality of Life of Individuals Aged 50+: The Positive Role of Internet Use. Cyberpsychology, Behavior, and Social Networking, 21(11), 694-702. DOI: 10.1089/cyber.2018.0170

Smith, J. A. (1996). Qualitative methodology: analysing participants' perspectives. Current Opinion in Psychiatry, 9(6), 417-421. DOI: 10.1097/00001504-199611000-00010

Swindell, R., Grimbeek, P., \& Heffernan, J. (2011). U3A Online and successful aging: A smart way to help bridge the grey digital divide. In J. Soar, R. Swindell, \& P. Tsang (Eds.), Intelligent Technologies for Bridging the Grey Digital Divide (pp. 122-140). IGI Global. DOI: 10.4018/978-1-61520-825-8.ch009

Tandoc Jr, E. C., Lim, D., \& Ling, R. (2020). Diffusion of disinformation: How social media users respond to fake news and why. Journalism, 21(3), 381-398. DOI: $10.1177 / 1464884919868325$

United Nations, Department of Economic and Social Affairs, Population Division. (2019). World Population Prospects 2019, Volume II: Demographic Profiles, accessed 7/6/2021, from https://population.un.org/wpp/Publications/Files/WPP2019_Volume-IIDemographic-Profiles.pdf

Wagner, N., Hassanein, K., \& Head, M. (2010). Computer use by older adults: A multidisciplinary review. Computers in Human Behavior, 26(5), 870-882. DOI: 10.1016/j.chb.2010.03.029 
Winter, P. F. (2011). The lived experience of social support for older adults in a computermediated environment: A phenomenological research study. Dissertation Abstracts International Section A: Humanities and Social Sciences, 72(4-A), 1405. http://ovidsp.ovid.com/ovidweb.cgi? T=JS\&CSC=Y\&NEWS=N\&PAGE=fulltext\&D=ps yc8\&AN=2011-99190-209

Woodward, A. T., Freddolino, P. P., Wishart, D. J., Bakk, L., Kobayashi, R., Tupper, C., Panci, J., \& Blaschke-Thompson, C. M. (2013). Outcomes from a peer tutor model for teaching technology to older adults. Ageing \& Society, 33(8), 1315-1338. DOI: $10.1017 / \mathrm{s} 0144686 \times 12000530$

Wright, K. (2000). Computer-mediated social support, older adults, and coping. Journal of Communication, 50(3), 100-118. DOI: 10.1111/j.1460-2466.2000.tb02855.x

Xie, B. (2008). Multimodal computer-mediated communication and social support among older Chinese internet users. Journal of Computer-Mediated Communication, 13(3), 728750. DOI: $10.1111 / \mathrm{j} .1083-6101.2008 .00417 . x$

Yellow. (2018). Yellow Social Media Report 2018: Part One - Consumers. Accessed 8/11/2018, from https://www.yellow.com.au/wp-content/uploads/2018/06/YellowSocial-Media-Report-2018-Consumer.pdf

Young C., Roberts R., \& Ward L. (2020). Enhancing resilience in the transition to parenthood: a thematic analysis fo parents' perspectives. Journal of Reproductive and Infant Psychology, 1-14. DOI: 10.1080/02646838.2020.1724916

Yu, R. P., McCammon, R. J., Ellison, N. B., \& Langa, K. M. (2016). The relationships that matter: Social network site use and social wellbeing among older adults in the United States of America. Ageing and Society, 36(9), 1826-1852. DOI: $10.1017 /$ S0144686X15000677

\section{Biographical Notes}

Belinda Grace Fuss is a Doctor of Philosophy (Psychology) candidate at The University of Adelaide, Adelaide. Her doctoral thesis investigates the potential for older adults to foster social and psychological wellbeing by communicating with others through computers. Belinda has worked as a research assistant on projects across the domain of Health and Medical Science and is currently completing her postgraduate study.

Diana Dorstyn is a registered psychologist and Senior Lecturer in the School of Psychology at the University of Adelaide, where she teaching and coordinates postgraduate courses. Her research and teaching is in the areas of clinical and health psychology, with a particular interest in improving quality of life outcomes across the lifespan and the use of telecommunication technologies in psychology service delivery.

Lynn Ward is an established researcher within the Psychology community, with specific interest in the factors that influence adult development and ageing such as the impact of lifestyle choice and health habits, resilience, successful ageing, and cross-cultural issues. She currently works as a Visiting Research 
Fellow within the School of Psychology at The University of Adelaide.

\section{Appendix A: Interview Questions}

Table 2: Interview schedule

Question
What do you think are the
most beneficial aspects of
being able to communicate
online?

\section{Prompt/s}

What about for yourself/for your social network/for your community?

What are some challenges or limitations you've experienced online?

How do you manage the

Can you tell me about when you feel most comfortable online?

Can you tell me about a time where you felt uncomfortable online? (What did you do in response?)

Can you talk about a circumstance that would cause you to swap from talking online to calling or seeing that person in person?

Can you tell me about an activity available online that you have no time for?

How much choice do you feel you have over who contacts expectations of those you communicate with? you?

How obligated do you feel you are to reply to everyone who contacts you?

Can you tell me about a time when someone you don't know or no longer talk to contacted you?

Can you tell me about a time when you've performed a

What has your experience companionable task while talking online? (e.g., making been with engaging your community online?

dinner talking to family over skype, watching a tv show and chatting about it online?)

Can you tell me about an online group that's specific to your particular interests or identity?

Can you tell me about a time you've talked through a concern with a member of your community?

What are your experiences with meeting new people online?

\section{Appendix B: Coding}

Table 3: Breakdown of the Belonging; Experiencing Social Networks subtheme showing basic themes, components, and quotes illustrating the data.

Subtheme

$$
\text { Basic Theme Components Descriptive quote }
$$

\begin{tabular}{lllll}
\hline & Almost & as & Multimedia interaction "I don't think this ease of \\
Sharing news good. & is rich, frequent, communication has been a \\
and catching $\mathrm{N}=12$ & immediate, & precondition for people spreading
\end{tabular}




\begin{tabular}{ll}
\hline up. & asynchronous. \\
& Exchanging news and \\
& 'keeping up to date'. \\
& No-one misses out. \\
& Communication across \\
& time and circumstance. \\
& Maintenance of strong \\
& relationships despite \\
& barriers.
\end{tabular}

Keeping private things private. $N=12$

Warts

Participating all. in the $N=9$ moment. $N=11$

whether something is safe. deal.

$N=5$ inane, saccharine, attention-seeking details. Those details are valuable when they help me feel close to something I want to be involved in.

and Participation around the world and living in other cities but it certainly makes it much more easy to maintain family ties so um, y'know, I have two children who live in Sydney, and so l'm able to communicate with them by Skype or or or WhatsApp- so WhatsApp uh is all very useful because ... - so I am assured by my children - that it's very limited in who can see it so yes, you just leave- be quite relaxed and y'know frequent communication" George, $\mathrm{M}, 70$

The 'wrong' people can "I have also had um scammy things access personal l've recognised which have made information. I am a me feel uncomfortable, like um oh target because I have a a couple of times um PayPal or ah profile online. It's ostensibly PayPal has contacted uncomfortable, me and said that there's something annoying, a cause for wrong, they'll have to close my pity in others. I am account tomorrow, and um I know responsible for my own the background of that so l've- um security, I am it still makes me feel 'ugh' competent around my somehow ah- ah- um- er- bitsecurity, I make slightly stick to the stomach" Faith, judgements about $F, 76$

So what? Big People share boring, "I've got a friend in my running club

in, "...we do some remote babysitting contribution to activities and entertainment yeah, it's quite with immediate or entertaining, she takes herself off delayed response. to the toilet and tells us- she's only Sense of unfiltered three, but she says 'l've gotta go to togetherness, the toilet' so the conversation, the closeness with family call keeps going but she runs off to and friends. the toilet but sometimes she'll call out to us from the toilet etcetera etcetera .... it's whatever- what happens if she went outside we're not quite sure but this is- might be while her mother is having a shower or cooking- getting dinner ready or something like that so she's there but she's not immediately in the room um and we 
read to her and blend her colours in with her etcetera" Nate, M, 69

We just don't It can be too “...they're- they're not home that do it. complicated, take too much I don't think ... when they're $N=6 \quad$ much time, they're too busy they- they don't worry about busy: it's uncomfortable whatever calls they miss, they just, it's not worth the effort. I uh they have notices saying uh feel like I miss out "una- unavai-" uh 'I I am unavailable versus I'm not missing at present', yeah, and that's fine." out on anything. Glen, $\mathrm{M}, 80$

Note: $N$ refers to the number of participants contributing to the theme

Table 2: Breakdown of the Belonging; Building Interests and Identity subtheme showing basic themes, components, and quotes illustrating the data.

\begin{tabular}{llll}
\hline Subtheme & Basic theme & Components & Descriptive quote \\
\hline \multirow{3}{*}{ Broadcasting } & These are & Socialising with similarly minded "I'm a lot more \\
my & others beyond scheduled meet-ups. involved with um not
\end{tabular}

information. interests. Forming and maintaining social for profit $N=12 \quad N=12$ interest groups. Engaging with organisations- let me identity when formal clubs don't exist. put it that way- um I can use my expertise despite being than I used to be um retired. I feel empowered as part of things like change.org society at large. I feel like I contribute. or UNH- UNHCR or even political or climate environmental organisations um and often on Facebook people put all sorts of things these days including non-social so political commentary or or um links um and I find I'mI feel more free to communicate as a um sort of just one of the masses um so to speak than I might do if if it was a more personal um personalised face-toface communication" Faith, F, 76

I don't want Platform for misinformation, fake "...then you come to see that. news, offensive content. I don't want across something on $N=3 \quad$ to be involved, I don't want to see that. This is the wrong place for that. I can maintain my own boundaries by talking to others, changing settings, ignoring it. I respect the boundaries of others.

yanno the um the uh the white supremacy movement or whatever else you think hang on not only is it inappropriate but uh um yanno need to be very careful what 


\section{Participating} in interest $N=11$

group activities.

$N=12$ you're allowing other people to post on under you name" Peter, M, 69
Feedback and scrutiny. $N=6$
My effort wasn't appreciated, I feel ignored/dismissed/anxious/exposed. It doesn't matter what others say, I don't get discouraged.
Exploring I can find information about my online. interests/identity, other people with similar interests/identities. I can have fun, be stimulated, feel affirmed. I can have incidental exchanges with strangers doing the same task. I can meet new people.
The last I'm not interested in meeting new thing l'd people, I'm content with the people I want to do. know. I have a small group of close $N=4$ friends.
"Al says 'oh l'd like to put that on Facebook, mum' and I thought well it's not going to hurt it's only the barbeque. But I found myself asking him did he get any responses, I was looking for the response from people. Now I don't- I don't need the response. If he hadn't had put it on the bloody Internet I would've not- I knew I did a good job." Janet, F, 70

"[Dating is] probably one of my fun parts of the going on the computer on um working- oh- talkingcommunicating on the computer ... yeah those prob'ly they probably provides me um if I feel- sort of feel as if I'm fee- really miserable then l'll start going to do things online like that." Cathy, F, 74

"I've got a a fair lot of things on that I do socially as and uh I don't really uh rerequire to uh use the uh um much more social activities than than what I have ... I'm very very lucky for an old person, I have so much going on, and at my pace." Glen, M, 80

And then I People aren't who they say they are. "I just say nicely yanno block them. They could be anyone. People can 'I really don't think we $N=4$ say whatever they want because it's anonymous. Strangers are rude, offensive. I can maintain my own similar- simi boundaries by checking details, by ... so maybe that we 
avoiding, by blocking certain people.

Despite
social
distancing.
$N=7$

Participate in, contribute to activities. Attend classes, meetings. I can keep attending despite barriers. Online meetings are a facsimile to face-toface meetings.

$\begin{aligned} & \text { Not the There is less appeal/incentive to "some- some friends } \\ & \text { same. } \\ & N=4 \\ & \text { meet online. Meeting online is not as of mine I know they } \\ & \text { good as face-to-face. It's more Zoom together and } \\ & \text { difficult to attend online. Some people they have with this } \\ & \text { can't/are too old to attend online. }\end{aligned} \begin{aligned} & \text { virus they're having } \\ & \text { coffee mornings } \\ & \text { together with zoom } \\ & \text { and that sort of thing } \\ & \text { but I don't do that" Lily, } \\ & \text { F, } 69\end{aligned}$

Table 3: Breakdown of the Support overarching theme showing basic themes, components, and quotes illustrating the data.

\begin{tabular}{llll}
\hline Subtheme & Theme & Components & Descriptive quote \\
\hline $\begin{array}{l}\text { Supporting } \\
\text { others. }\end{array}$ & Providing & I can do things online "[a friend] in London was out of \\
$N=12$ & $N=9$ & $\begin{array}{l}\text { that help. I can provide work, wanted a loan, and he asked } \\
\text { instrumental support for it over the email and um, I } \\
\text { online. Others can ask responded over the email and then }\end{array}$
\end{tabular}


me for instrumental I transferred money from my UK help online. I have bank to him over the internet ... knowledge that can now that's personal, isn't it?" Cecil, help. I am able to talk $\mathrm{M}, 80$.

things through.

I don't ask for I provide support, I don't "Well no, she had enough of her support. receive it. I would be own [problems] she doesn't need $N=2 \quad$ imposing. I have to go it to be burdened any further ... I just alone. I'm aware this is feel as though it was for me to say unfair to me. what I could say, but certainly not to impose any- any issues of my own." Jessie, F, 81.

Online I can see why they "So now l'm finding some of those support, it's a would do that but it's not confide with each other on last resort. for me. It's good that $N=5$ they have that support. I Facebook or that sort of thing, and wouldn't share my problems in public. I'd find help online if I really needed it.

How do I tell? Some people don't “...y'know you've got particular $N=2$ signal a need for support. I have to rely on second-hand news or incidental moments to know there's an issue. It's on me to check in.

No one uses The telephone isn't an the phone option. People don't anymore.

$N=2$ want to have actual conversations

anymore. The way

\section{R U Okay?} $N=10$ l care, people want to talk doesn't suit me. Some people can't use the internet, they're too old. It's hard to plan when to call, I might be

I care, they Messages show that someone

Sending cares. shows availability I am happy for people to share with me. I will reply immediately if someone asks. Prearranged agreements to contact if needed. It's easy to signal availability or need vs. it's painful friends who can provide you with support and help, and other ways it's very frustrating because other people don't use the system, thethey- the electronic um y'know when- um, to keep in contact, but they won't do anything else to keep in contact." Cathy, F, 74.

"so um you you know I I never know if I ring her I'm going to be intruding at the wrong time and ... um and a 'cos she's free to ring me ... but she doesn't often." Jessie, $F, 81$.

...just sorta say 'hi how you going how-' ah particularly now 'is everything okay with you' and they come back and say 'yeah that's fine, how about you'. Cathy, F, 74. 


$\begin{array}{ll} & \text { when others don't } \\ & \text { engage. } \\ \text { Sensitive } & \text { It's more "I think a real time verbal } \\ \text { topics move } & \text { appropriate/intimate to conversation is a much more } \\ \text { offline. } & \text { call. It's easier to talk at effective in conveying nuance and } \\ N=5 & \text { length when calling, l'm understanding than the Facebook } \\ & \text { too long-winded for post or anything." George, M, 70. } \\ & \text { CMC. It's easier to read } \\ & \text { facial cues and } \\ & \text { emotions in person. } \\ & \text { There's more nuance in } \\ & \text { verbal conversation. } \\ & \text { You can clarify things } \\ & \text { easier verbally. }\end{array}$

